Journal of Education and Vocational Research

Vol. 5, No. 2, pp. 65-72, June 2014 (ISSN 2221-2590)

\title{
Dropout in High Schools students-Modeling a Case Study in the Vhembe District, Limpopo Province, South Africa
}

\author{
Kwabena A. Kyei \\ University of Venda, Limpopo province, South Africa \\ Kyei61@gmail.com
}

\begin{abstract}
South Africa experiences a significant amount of dropouts of high school learners every year. Only about $45 \%$ of learners who start primary school in a given year write matriculation examinations after 10 years of schooling. A high dropout rate deprives the country of well-informed and competent future leaders. This study looks at the factors that underlie dropout in high schools in the Vhembe district. A random sample of 5 villages was selected from 25 villages which have high schools. A census of high school dropouts in these 5 villages was conducted. About 660 dropouts were obtained and interviewed. Applying regression modeling, this study shows that poor performance, attitude, punishment and pregnancy are the factors affecting dropout in Vhembe, and recommends that educators encourage learners to develop positive attitude to school work and also give extra assistance to under-performing learners, and sex education be given with seriousness to reduce unwanted pregnancies.
\end{abstract}

Keywords: Attitude, punishment, pregnancy, learners, dropout, educators

\section{Introduction}

Before the new democratic South Africa was borne, black people were discriminated against and denied quality education by the apartheid policies. They were not allowed to study for certain programs/degrees, rather they were forced to study some restricted courses or disciplines and could not study for higher qualifications. They had no access to some basic educational infrastructure like libraries, laboratories, etc. But now all have changed and more public and private schools are being built, colleges, university of technologies and universities are springing up all over the country. There are free schools feeding schemes, free education in public high schools, bursaries, loans, and scholarships for those who want to further their studies at the tertiary level. The problem now, according to Prof Motala of the University of Johannesburg, is that much higher proportion of the learners drop out without completing high school. She stated that: "it is now expected that academic aspirations and performance particularly among the black population would go up and the dropout rate of learners in high schools will go down. But I think about 45\% of a cohort of learners who start grade $\mathrm{R}$ in a given year survive to write matriculation examinations after 10 years, which means that a great number (55.5\%) of children are falling by the wayside," (http://learningenglish.voanews.com).

The UN convention on the Rights of the Child (articles 28 \& 29) states that every child under the age of 18 years should be given the right to education that develops their personality and talents without overlooking and discounting their physical and mental abilities and potentials (www.unicef.org/southafrica/SAF_resources). Therefore if some of the children do not get that opportunity it becomes disturbing because the nation's future leaders are being denied appropriate skills and knowledge for development and good governance. The results of matriculation examinations of 2012 (final examinations for high school learners in 2012), released on the $3^{\text {rd }}$ January 2013, showed that only about 44\% of the cohort of pupils who entered the school stream 10 years ago successfully completed high school in December 2012 (The Star Newspaper, 3 January 2013, pages 2-3; The Times Newspaper, 3 January 2013, pages 3 - 5). This study looks at the factors underlying high school dropout in the Vhembe district of Limpopo of South Africa, and tries to make recommendations that it is believed, when executed, will enable the problem of dropout reduced or solved. 


\section{Background}

Limpopo province \& Vhembe district: The Vhembe district is one of the five districts in the Limpopo province. The Limpopo province is in the north of the country and shares international borders with Botswana, Mozambique and Zimbabwe. The province covers a land size of $123910 \mathrm{~km}^{2}$; comprising about 10.2 percent of South Africa's total land area \{Statistics South Africa, (StatsSA), 2003\}.The total population of the Limpopo province, according to 2011census, is 5404868 representing $10.4 \%$ of South Africa's total population. More than half of its population is female (i.e. 53\%). The total population in the Limpopo province or the Vhembe district is mainly African about $97.2 \%$. Nearly half (49\%) of the economically active people in the province are unemployed and $33 \%$ of the employed were in the informal sector. Poverty prevalence was very high, as 6 in every 10 persons fell below the poverty line in 2002 (StatsSA, 2003).

\section{Literature Review}

Factors affecting Dropout: The following are cited in the literature as important factors affecting dropout in high schools: Motivation to learn; attitude towards learning; substance abuse; encouragement by teachers; peer pressure; pregnancy; and poor performance. When learners are motivated they build some confidence which results in learners performing very well thereby reducing the rate of dropping out (Mullins, 2005: 39; ul.netd.ac.za). The maintenance of high motivation influences psychological and social functioning and facilitates academic performance (Gilman \& Anderman, 2006: 375-391). Sanchez (2000) proposes that the way students define themselves determines their success or failure in the future. Thus self-concept or attitudes formed throughout life as a result of social integration and socialization process, counts much for their success or otherwise. The negative attitude towards learning invariably causes learners to perform poorly. When a learner loses interest in attending school because of negative attitude or for other various reasons, he/she is bound to perform poorly. Similarly if she/he gets into bad habit - smoking, drinking, and truancy - the learner will not perform well and will consequently drop out (ul.netd.ac.za). Substance abuse refers to alcohol and drug abuse. Learners who are addicted to alcohol and drugs tend to drop out to work (car wash, taxi driving, security job, etc.) to get money so that they can buy those substances. Thus substance abuse can change ones attitude towards learning leading to a dropout. Moreover attitude to schooling becomes negative when learners take substances and that very often leads to dropout (Hodgekinson, 1990). The abuses of such substances hamper the ability of the learner in several ways; including crime and recklessness. Most crimes committed at schools involve substance use (Cunningham, 1993: 272).

Marchesi \& Martin (2002) conducted research in Spain and found that the relationship between the learner and educator is one of the factors that determine academic performance. How the teachers carry themselves, their lifestyles and their accessibility or otherwise, all affect learners' attitude to learn. Castejon and Perez (1998) found that educator's expectations significantly influence the learner's performance. There is a positive relationship between the educator's motivation and that of a learner, and the socio-metric status of the learner affects performance both directly and indirectly, (Georgiou, 2002; Kriek \& Grayson, 2009: 185203). Peer pressure results in negative decisions, rebellion and moody behavior, which in turn results in poor academic performance and dropout (Sharry, 2004: 1-3). Research by Buote (2001) indicates that there is a positive correlation between academic performance and peer relationships. Learners found to be rejected tend to perform poorly. Most pregnant learners drop out of school because of several different reasons. According to Lynette Vermaas, (Student Development and Support Practitioner at the Directorate of Student Development and Support of Tshwane University of Technology in Pretoria, in South Africa), the increased unplanned pregnancies and the effects contribute greatly to dropout. Students experience post-abortion stress symptoms grievously affecting their psychological well-being, and ultimately leading to poor academic performance and dropout (www.vuma.ac.za). If learners perform poorly (repeat the same grade several times), they tend to lose hope and decide to drop out. Research studies indicate that repetition is a strong predictor of dropout and that there is a strong correlation between repetition and dropout. In 2007, a third of all children at school in South Africa had repeated a grade; and in the year 2009, 9\% of learners enrolled in schools were repeating the grades of the previous year (DoBE, 2011: 4). 


\section{Methodology}

Materials/data: A random sample of 5 villages was selected from 25 villages in the district which have high schools. A census of high school dropouts in these 5 villages was conducted. About 660 dropouts were obtained and interviewed. A structured questionnaire was used in the interview. Some of the questions in the questionnaire were the following: Are you a drop-out of school?; Which grade were you when you dropped out?; What made you to drop out; (poverty, punishment, pregnancy, family matters, poor academic performance/ repeat)?; Did you repeat a grade before?; If poverty was the main reason, what did you need money for? (To pay fees, buy uniform, money for transport to school, money for books)? what is the distance from your home to school?; what is the mean family monthly income? (Less than R1000, R1001-R2000, R2001 -R3000, R3001 - R5000, R5001 and above)? Do you have friend who have dropped out?; If yes your friends and you, who dropped out first?; How old are you, your friends, etc.?

Methods/analysis: After basic statistical analyses, logistic and multiple regression analyses were also done. The logistic model formula computes the probability of the selected response as a function of the values of the predictor variables (Hosmer and Lemeshow, 2000: 47).

\section{Results}

Table 1 shows that $24.4 \%$ of learners dropped out of school because of pregnancy, $15.2 \%$ dropped out because of poor performance, $36.6 \%$ dropped out because of negative attitude towards learning, and $12.9 \%$ dropped out because of punishment. The percentage of learners who dropped out because of substance abuse is 5.8, and that of those who dropped out because of family matters is 2.8 , while those who dropped out because of finances is 2.5.The three variables, viz.: attitude, (36.6\%), pregnancy, (24.2\%) and performance, (15.2\%) constitute 76 percent of the dropouts' cases. Punishment contributes about $13 \%$. The proportion of learners who dropped out because of finances is insignificant at $2.5 \%$. Table 2 shows that the mean age of the respondents at the time of interview was 21.7 years. Since some of the learners had dropped out earlier before the interview, it could be assumed that the learners drop out of school at the age of about 20 years. Almost all the respondents dropped out in grade 10 after repeating grade 9 for some time.

\section{Table 1: Distribution of factors affecting dropout}

\begin{tabular}{lll}
\hline Variable & Frequency & Percentage \\
\hline Pregnancy & 160 & 24.2 \\
Performance & 100 & 15.2 \\
Attitude & 242 & 36.6 \\
Punishment & 85 & 12.9 \\
Finance & 17 & 2.5 \\
Substance abuse & 38 & 5.8 \\
Family matters & 18 & 2.8 \\
Total & 660 & 100.0 \\
\hline
\end{tabular}

The initial analyses, including chi-square tests, show that there is a very strong relationship between dropout and pregnancy ( $p$-value $=0.000)$; between the dropout and performance ( $p$-value $=0.000)$; between dropout and attitude $(p$-value $=0.000)$ and between dropout and punishment $(p$-value $=0.000)$. Learners tend to dropout after they have been punished. Though the proportion of dropouts from financial problems is insignificant, finances still have strong relationship with dropout because of its p-value i.e. ( $p$-value $=0.009)$. [The table for chi-square tests was deleted to reduce the number of pages to 10 or less.] There is a very strong relationship between dropout and substance abuse $(p$-value $=0.000)$. Family matters do not appear to contribute much to dropout because from the Table 1, learners who drop out due to family matters constitute only $2.8 \%$. Although family matters contributes only $2.8 \%$, the $p$-value of 0.044 , suggests that there is some relationship between family matters and dropout.

Results from Logistic Regression: Results from the Logistic Regression seen in Table 3 confirm that pregnancy, poor performance, negative attitude to studies and punishment are the factors influencing dropout. 
Mathematically, the model is given by:

$\operatorname{Logit}[\theta(X)]=\log \left[\frac{\theta(X)}{1-\theta(X)}\right]=\alpha+\beta_{1} X_{1}+\beta_{2} X_{2}+\cdots+\beta_{i} X_{i}$

Specifically, the model is:

Log odd (dropout) $=64.301-4.329$ pregnancy -4.386 performance -4.299 attitude -3.894 punishment 3.693 family matters -22.497 substance abuse -22.698 finance.

This implies that

Odd ratio (dropout) $=8.423 \mathrm{E} 27+0.013$ pregnancy +0.012 performance +0.025 family matters +0.014

attitude +0.020 punishment.

\section{Table 2: Other indicators affecting dropout}

\begin{tabular}{|c|c|c|}
\hline Mean age of respondents & & 21.7 years \\
\hline Mean distance between home and school & & $2.84 \mathrm{kms}$ \\
\hline Mean family monthly income & & R 1680 \\
\hline Did you repeat a grade before dropping out? & Yes & $83.8 \%$ \\
\hline & No & $16.2 \%$ \\
\hline If yes which grade did you repeat? & Grade 9 & $96 \%$ \\
\hline & Other grades & $4 \%$ \\
\hline Which grade did you drop out? & Grade 10 & $99 \%$ \\
\hline & Other grades & $1 \%$ \\
\hline Do you have friends who have also dropped & out? Yes & $36.2 \%$ \\
\hline & No & $63.8 \%$ \\
\hline If yes, who dropped out first? & Some friends & $33.8 \%$ \\
\hline & my)self & $53.2 \%$ \\
\hline & Same time & $13.0 \%$ \\
\hline Friends who dropped out first older than you & u? Yes & $23.5 \%$ \\
\hline & No & $22.4 \%$ \\
\hline & Same age & $54.1 \%$ \\
\hline Have you ever smoked? & Yes & $22.2 \%$ \\
\hline & No & $77.8 \%$ \\
\hline Do you smoke? & Yes & $19.9 \%$ \\
\hline & No & $80.1 \%$ \\
\hline Have you ever used drug? & Yes & $4.5 \%$ \\
\hline & No & $95.5 \%$ \\
\hline Are you working now? & Yes & $14.9 \%$ \\
\hline & No & $85.1 \%$ \\
\hline
\end{tabular}

Table 3: Variables in the equation of learners' dropout

\begin{tabular}{lllllll}
\hline Variables & B & SE & WALD & Df & Sig & Exp(B) \\
\hline Pregnancy & -4.329 & 0.486 & 79.352 & 1 & 0.000 & 0.013 \\
Performance & -4.386 & 0.613 & 51.118 & 1 & 0.000 & 0.012 \\
Attitude & -4.299 & 0.396 & 117.709 & 1 & 0.000 & 0.014 \\
Punishment & -3.894 & 0.545 & 51.040 & 1 & 0.000 & 0.020 \\
Finance & -22.698 & 12710.141 & 0.000 & 1 & 0.999 & 0.000 \\
Substance abuse & -22.497 & 7925.546 & 0.000 & 1 & 0.998 & 0.000 \\
Family matters & -3.693 & 1.066 & 12.007 & 1 & 0.001 & 0.025 \\
Constant & 64.301 & 14978.711 & 0.000 & 1 & 0.997 & $8.423 \mathrm{E} 27$ \\
\hline
\end{tabular}

Multiple Regressions: The results from the general linear model and regression analyses seen in Table 4 confirm that indeed pregnancy, performance, attitude and punishment are the most important predictors of dropout. Substance abuse marginally influences dropouts. The model from this analysis is as follows:

Dropout $=0.210+0.688$ pregnancy +0.716 performance +0.708 attitude +0.671 punishment +0.729 substance abuse +0.790 finance +0.573 family matters

(Unstandardized) 
Dropout $=0.503$ pregnancy +0.423 performance +0.607 attitude +0.371 punishment +0.277 substance abuse +0.200 finance +0.152 family matters

(Standardized) (5)

Table 4: Coefficients of Dropouts

\begin{tabular}{|c|c|c|c|c|c|}
\hline \multirow[t]{2}{*}{ Model } & \multicolumn{2}{|c|}{$\begin{array}{l}\text { Unstandardized } \\
\text { coefficients }\end{array}$} & \multirow[t]{2}{*}{$\begin{array}{l}\text { Standardized } \\
\text { coefficients }\end{array}$} & \multirow[t]{2}{*}{$\mathbf{T}$} & \multirow[t]{2}{*}{ Sig } \\
\hline & B & Std. Error & & & \\
\hline Constant & 0.210 & 0.019 & & 11.104 & 0.000 \\
\hline Pregnancy & 0.688 & 0.037 & 0.503 & 18.638 & 0.000 \\
\hline Finance & 0.790 & 0.102 & 0.200 & 7.731 & 0.099 \\
\hline Substance abuse & 0.729 & 0.069 & 0.277 & 10.645 & 0.095 \\
\hline Performance & 0.716 & 0.045 & 0.423 & 15.815 & 0.000 \\
\hline Family matters & 0.573 & 0.097 & 0.152 & 5.894 & 0.102 \\
\hline Attitude & 0.708 & 0.032 & 0.607 & 22.085 & 0.000 \\
\hline Punishment & 0.671 & 0.048 & 0.371 & 13.990 & 0.008 \\
\hline
\end{tabular}

Dependent variable: why did you drop out from school?

Discussion: Table 2 provides some important information. The average distance between the home and the school of a dropout learner is a mere 2.84 kilometers with a standard deviation of 1.3 kilometers. This means that learners do not really travel long distances to school therefore the distance could not prompt dropout. The average family monthly income is R1680 (approximately $\$ 200 / \mathrm{m}$ ) and yet, poverty does not seem to contribute to dropout because only $2.5 \%$ of dropouts was due to finance. Almost all the dropouts (96\%) did so in grade 10 after repeating grade 9 for some time. Principal, educators and all stakeholders need to find out what is there in grade 9 that causes learners to fail and lose interest in further studies. A priori one can imagine that grade 9 corresponds to age of puberty for most learners. Maybe this physiological change in their bodies makes them lose focus. Table 2 further shows that dropping out of school does not depend on peers' influence, because about $64 \%$ of the dropouts did not have friends who had dropped out. We note from the table that individuals dropped out before their friends ever did therefore their dropping out could not come from unwise suggestions from friends. The table again informs that neither age nor substance could influence dropout because only $4.5 \%$ or $22.5 \%$ of the dropouts ever used drugs or smoked. The results from various methods conclude that negative attitude to studies; pregnancy, poor performance, and punishment are the factors affecting dropouts in Vhembe schools. The results are in line with other studies (Sanchez, 2000; Mullins, 2005; Gilman \& Anderman, 2006). But the standardized multiple regression model in equation 5 shows that attitude (negative) is the most effective predictor of dropout, more effective than pregnancy and performance. As seen earlier, about $36.6 \%$ of the respondents dropped out because of their (negative) attitude towards learning. Attitude refers to the way one values or thinks of school. A positive attitude leads to good performance and a negative attitude leads to poor performance.

Pregnant student normally perform poorly because the pressure of school work puts much stress on them. Some of the reasons given by pregnant girls for dropping out of school include the following:

- We have to take care of the baby, if there is no one to look after the baby for us;

- The pressure becomes too much for us;

- Some teachers abuse us emotionally;

- We become ashamed of ourselves;

- Some learners tease us;

- We do not want people to know about the pregnancy;

- Some of us are afraid of the teachers who impregnate us;

- The pregnancy makes us perform poorly.

Learners who perform poorly or who are continuously failing tend to lose hope and start to develop a negative attitude towards learning which aggravates the situation and leads to dropout. Peer pressure also influences attitude. An associate or a companion can influence positively or negatively therefore learners should be careful about the companions/associates they pick and moves along with. 
Punishment causes dropouts because male learners having girlfriends feel humiliated when they are punished before their girlfriends. In the same vein female learners who have boyfriends do not find it pleasant when they are punished in front of their boyfriends. Punishment can be a corporal punishment, detention, suspension, expulsion, disciplinary hearing, etc. In a related study it was found out that $89.8 \%$ of learners are disciplined by corporal punishment from their educators and the principals 9Kyei \& Maboko, 2012; Kyei \& Maboko, Department of Statistics, University of Venda, Thohoyandou, unpublished paper/personal communication). This takes place especially in public schools and learners do not like it, so that is how punishment also causes learners to drop out. Professor Motala of the University of Johannesburg is worried about the huge numbers of learners who do not complete high school. The cohort of pupils who entered the school stream in 2002, the "matric" examinations results released on 3 January 2013 showed that only $44 \%$ successfully passed out (The Star newspaper of January 3, The Times newspaper of January 3, 2013) implying that over $54 \%$ of the cohort have failed. Her concern is that South Africa has over $24 \%$ unemployment rate therefore students in high schools who drop out would find it very difficult to compete with graduates from colleges in search for jobs (except unskilled jobs). The case of job-hunting for these high school dropouts will be hopeless! Graeme Bloch and some researchers advance that South Africans do not produce mathematics and science graduates. They explain that many schools, especially schools in the rural areas, do not have well-equipped laboratories (Bloch, 2012) that make it difficult for them to train mathematics and science graduates. Ninety-two percent of the schools do not have libraries and in many cases, teachers and school principals do not have the skills or training to do their jobs (DoBE, 2011: 4).

South Africa's minister of basic education promised a number of improvements when she said that teacher development exercises would be rolled up some two years ago. She stressed that the focus of the development would be on subject and content knowledge, and that effort would be made to get right teachers in the jobs (www.celebritynetworth.com/watch/mr1). But is this happening? It is two years now! When shall we see this implemented? In 2012, school textbooks were supplied to some schools in the Limpopo province only 3 months before the end of the year. Thus some schools in the province stayed without textbooks for more than eight months. The foregoing discussion permits us to say that the following are important factors affecting dropout rate of learners in high schools in Vhembe: attitude to studies, pregnancy, poor performance and punishment. Most pregnant learners tend to perform poorly academically because they are unable to handle the pressure of pregnancy and this changes their attitude towards learning. Most learners do not like corporal punishment and most schools prefer it, therefore that puts them in a collision course and learners tend to quit school when punished. Learners who have challenges at home oftentimes develop negative attitudes to school work and invariably perform poorly and dropout. Financial problems do not necessary affect dropout directly, but continued financially difficulties where learners cannot afford to buy school uniform for example, and other basic school needs, including money for transport to school, can lead to deterioration in performance. Substance abuse (drug and alcohol) only marginally affects dropout; but it also makes learners undisciplined and truant. Academically weak students turn to drop out.

\section{Conclusion}

The study has shown that most of the dropouts (99\%) in high school do so in grade 10 after repeating grade 9. The average age of dropouts is about 20 years. It further concludes that the most predictive factors underlying dropout are (negative) attitude, pregnancy, poor academic performance and punishment. One expected poverty and substance abuse would contribute to dropout but this study has proved otherwise; these variables do not (directly) affect dropout. The statistical methods (multiple regression and logistic regression) confirm that the above-mentioned variables are the most predictive determinants of dropout in this study. The study wants to recommend the following to all stakeholders, particularly to the SMT and DoE.

Recommendations: The School Management Team (SMT) is to ensure that educators spend extra time to identify and help under-performing learners. They should help them in solving problems after school hours. They should devise measures and strategies to deal with problems that affect academic achievement right from the beginning of the year. Educators should collaborate with social workers to help learners that may have family problems. Teachers should be encouraged to teach learners to develop positive attitudes towards learning. Learners should know and understand the importance of education. Furthermore, educators are to give corrective punishments to learners by telling erring learners to write a lot of essays or solving a number 
of problems instead of subjecting them to corporal punishment. The Department of Basic Education (DoBE), on the other hand, should make some policy guidelines to instruct schools to have compulsory sex education. That sex education lessons be taken very seriously to prevent high teenage pregnancy. That any male educator, including principals, seen to have any carnal knowledge of any female learner in his school, in particular, be sent to prison outright without any option of fine. This study though reveals important factors affecting dropout of learners in high schools, further studies can still be conducted to answer more questions about the factors contributing towards dropouts in high schools.

Note: DoBE: Department of Basic Education

UN: United Nations

Students: High school learners

Educators: High school teachers.

\section{References}

Bloch, G. (2012). Voice of America (VOA) special English Education Report. (http://learningenglish.voanews.com/content/high-dropout-rate-a-problem-for-south-africa). Retrieved 22 October 2012.

Buote, C. A. (2001). Relations of autonomy and relatedness to School functioning and psychological adjustment during adolescence. Dissertation abstracts, International Section A. Humanities and Social Sciences, 62(1).

Castejon, J. L. \& Perez, A. M. (1998). A Casual-explicative model of psycho-social variables in academic performance. Revista Bordon, 50(2), 171 - 185.

Cunningham, B. (1993). Child Development. New York: Haper Collins Publishers.

Department of Basic Education (DoBE). (2009). Teenage pregnancy in South Africa - with a special focus on school-going learners.www.education.gov.za. Retrieved 12 December 2012.

Department of Basic Education (DoBE). (2011). Report on Dropout and Learner Retention Strategy. DoBE: Pretoria, June 2011.

Georgiou, S. (2002).Teachers attributions of student's failure and teacher's behavior towards the failing student. Psychology in Schools, 39(5), 583 - 596.

Gilman, R. \& Anderman, E. M. (2006).The relationship between relative levels of motivation, intrapersonal, interpersonal and academic functioning among older adolescents. Journal of School Psychology, 44, $375-391$.

Gonzalez, M. C. (1998). Academic motivation. It's determining factors and guidelines for intervention. Navara: EUNSA.

Grant, M. \& Hallman, K. (2006). Pregnancy-related School dropout and Prior School Performance in South Africa. New York: The Population Council. 32pp.

Hodgekinson, H. L. (1990). The demographic of American Indians. Washington DC: Institute for Educational Leadership.

Hosmer, D. W. \& Lemeshow, S. (2000). Applied Logistic Regression. New York: John Wiley \& Sons.

Kriek, J. \& Grayson, D. J. (2009). A holistic professional development model for South African physical science teachers. South African Journal of Education, 29(2), 123 - 149.

Larose, D. T. (2006). Data Mining and Model. Hoboken: John Wiley \& Sons, Inc.

Marchesi, A. \& Martin, E. (2002). Evaluation in secondary education. Snapshot from a controversial era. Institute IDEA, Madrid: SN.

Menard, S. (1995). Applied Logistic Regression Analysis. London: Sage Publications.

Mullins, L. J. (2005). Management and organizational behavior, $7^{\text {th }}$ edition. London: Financial Times, Prentice Hall.

Prof Motala, S. (http://learningenglish.voanews.com/content/high-dropout-rate-a-problem-for-south-africa). Sanchez, J. (2000). The importance of self-esteem as a basis for the educational process. Surgam, 468, $41-47$.

Sharry, J. (2004). Counseling Children, Adolescents, and Families. London: Sage Publications

Statistics South Africa (StatsSA). (2003). Mid-year estimates. Pretoria: Government print.

The Star Newspaper, 3 January 2013 issue. South Africa local newspaper.

The Times Newspaper, 3 January 2013 issue. South African local newspaper. 
UN Convention on the Rights of the Child (www.unicef.org/southafrica/SAF_resources). Retrieved 12 December 2011.

Vermaas L Student Development and Support Practitioner at the Directorate of Student Development and Support. Report: TUT, Pretoria. 2011/01/25.

Vhembe District.(http://www:absoluteastronomy.com; Retrieved 12 May 2011.

http://www.celebritynetworth.com/watch/mr1. Retrieved 13September 2012.

http://www.unicef.org/southafrica/SAFresources.Retrieved 11 October 2011.

http://www.vuma.ac.za. Retrieved 15 November 2012.

http://www.ul.netd.ac.za.Retrieved 25 May 2014. 